\title{
CARACTERIZAÇÃO FLORÍSTICA E ECOLÓGICA DA ARBORIZAÇÃO DE PRAÇAS PÚBLICAS DO MUNICÍPIO DE GUARAPUAVA, PR ${ }^{1}$
}

\author{
João Alberto Kramer² e Rogério Antonio Krupek ${ }^{3}$
}

\begin{abstract}
RESUMO - Este estudo teve por objetivo realizar o levantamento florístico e avaliar algumas características ecológicas das principais praças públicas do Município de Guarapuava, região centro-sul do Estado do Paraná. Os trabalhos de campo foram realizados no período de janeiro de 2007 a março de 2009. Foram identificadas 98 espécies, distribuídas em 43 famílias. A abundância mensurada foi de 1.143 indivíduos. A espécie mais bem distribuída foi Tipuana tipu, enquanto as mais abundantes, Grevillea robusta e Platanus acerifolia. Com relação à origem, a maioria das espécies, tanto em riqueza quanto em abundância, é exótica. Os valores de riqueza, abundância, H' e equidade foram relativamente altos, enquanto que os de dominância e similaridade, foram baixos. Apesar do alto valor de riqueza e diversidade, a alta frequência de poucas espécies e o baixo número de indivíduos por área amostrada têm colocado as praças públicas da área avaliada em condições ecológicas ainda longe das ideais. O alto número de espécies exóticas reflete, ainda, a falta de interesse na conservação da flora regional.
\end{abstract}

Palavras-chave: Arborização urbana, praças públicas e diversidade

\section{FLORISTIC AND ECOLOGICAL CHARACTERIZATION OF ARBORIZATION OF MUNICIPALITY OF THE GUARAPUAVA, PR}

\begin{abstract}
The objective of present study were to carry a floristic survey and evaluate some ecological characteristics of principal squars public of municipality of the Guarapuava, mid-southern region of Paraná state. The sampling were carried out from January 2007 to March 2009. Were found 98 species distributed in 43 family. The abundance measured were 1.143 individues. The most widespread specie was Tipuana tipu, while the most abundance was Grevillea robusta and Platanus acerifolia. Regarding the origin, of the majoritary, both species and abundance are exotic. The richness, abundance, $H$ ' and equity values were relatively high while dominance and similarity values rere low. Despite the high value of richness and diversity, the high frequency of few species and low number of individuals for sampled area place the public squars in the area evaluated in intermediate ecological conditions. The high number of exotic species reflects, still, the lack of interet in the conservation of regional flora.
\end{abstract}

Keywords: Urban arborization, Public squars and Diversity.

\section{INTRODUÇÃO}

De maneira geral, as atividades humanas trazem reflexos imediatos à paisagem. Nesse sentido, paisagem urbana pode ser interpretada como o resultado das ações do homem nesse espaço. De forma genérica, são subdivididas em naturais e antropizadas, em que essa classificação considera a origem de seus elementos constituintes (HARDT; HARDT, 2007). Assim, paisagens naturais são aquelas que se originaram e se estabeleceram via processos naturais e as antropizadas, aquelas que sofreram algum grau de interferência humana no seu estabelecimento. Pela progressiva interferência humana, as primeiras podem paulatinamente ser transformadas

\footnotetext{
${ }^{1}$ Recebido em 02.12.2009 e aceito para publicação em 28.05.2012.

${ }^{2}$ Biólogo - Faculdade Guairacá, Guarapuava, Paraná. E-mail: <joaokramer@yahoo.com.br>.

${ }^{3}$ Universidade Estadual do Paraná, Campus de União da Vitória. Colegiado de Ciências Biológicas. E-mail: <rogeriokrupek@yahoo.com.br>.
} 
nas segundas, sendo representadas pela paisagem urbana. A mais comum e conhecida paisagem antropizada pode ser aqui representada pelas praças públicas, ambientes desenvolvidos pelo homem e que apresentam algumas características naturais.

Planejar a arborização de uma praça pública é indispensável para o desenvolvimento urbano, para não trazer prejuízos ao meio ambiente. A crescente urbanização da humanidade constitui preocupação de todos os profissionais e segmentos ligados à questão do meio ambiente, pois as cidades avançam e apresentam crescimento rápido e sem planejamento adequado, o que contribui para a maior deterioração do espaço urbano (LIMA NETO et al., 2007; LOMBARDO, 1985).

O conhecimento da flora urbana faz parte de um programa de estudos que toda cidade deveria se preocupar em desenvolver, visando a um plano de arborização que valorize os aspectos paisagísticos e ecológicos com a utilização, principalmente, de espécies nativas. Além dos benefícios que influenciam diretamente a vida do homem, do ponto de vista ecológico a arborização urbana é fundamental. Através dela, podese salvaguardar a identidade biológica da região, preservando ou cultivando as espécies vegetais que ocorrem em cada região específica.

Considerando esses pressupostos e levando em consideração a importância de áreas verdes dentro dos espaços urbanos, este trabalho teve os seguintes objetivos: i) conhecer a composição florística de algumas das principais praças públicas localizadas na área urbana do Município de Guarapuava; ii) quantificar as diferentes espécies ocorrentes e relacioná-las com a área disponível em cada praça pública; iii) aferir, através de diferentes índices, sobre as condições ecológicas em que se encontravam as áreas avaliadas; iv) classificar as espécies ocorrentes, de acordo com sua origem, em espécie nativa e espécie exótica; e v) comparar a situação atual das praças públicas do município, com relação à composição e diversidade florística, com estudos realizados em outras regiões do Estado e do Brasil.

\section{MATERIAL E MÉTODOS}

Este estudo foi desenvolvido em sete praças (1. Cândido Xavier de Almeida e Silva; 2. Praça da Ucrânia; 3. Eurípio Rauem; 4. Nove de Dezembro; 5. Coronel Luiz Daniel Cleve; 6. Parque do Lago; 7. Juscelino Kubistchek de Oliveira) de um total de 19 praças públicas localizadas no perímetro urbano da cidade de Guarapuava, região Centro-Sul do Estado do Paraná (Figura 1). As praças foram selecionadas por representarem as principais e mais visitadas áreas públicas do município. De modo geral, todas as praças avaliadas foram estruturadas inicialmente a partir de uma área remanescente de mata nativa de Floresta Ombrófila Mista, típica da região. Entretanto, com o passar do tempo a vegetação foi continuamente modificada através da adição planejada e espontânea de espécies exóticas.

Para o estudo, cada uma das praças foi visitada no período correspondente aos meses de janeiro de 2007 a março de 2009. Para a avaliação qualitativa, as informações foram obtidas através de análise visual das espécies ocorrentes em cada um dos locais (censo ou inventário total), anotando-se o nome vulgar e, ou, científico sempre que possível, além de algumas características das espécies (porte, presença de flores e frutos). Quando necessário, foi realizada a coleta de material botânico para posterior identificação. Essa foi desenvolvida utilizando-se a literatura apropriada e, ou, com o auxílio de um especialista para identificação ou confirmação. A identificação em família seguiu Souza e Lorenzi (2005). Na avaliação quantitativa, foi contado o número de espécimes ocorrentes de cada uma das espécies registradas nas praças estudadas.

Para a análise dos dados foram calculados, em cada uma das praças selecionadas, os seguintes parâmetros: a) riqueza de espécies; b) abundância de espécies; c) índice de diversidade de Shannon-Wiener: $\mathrm{H}^{\prime}=\Sigma$ (pi) (log pi), em que pi = abundância da espécie na área; d) índice de dominância de Simpson: $\mathrm{C}=\mathrm{a}(\mathrm{Xj} /$ $\mathrm{Xo}$ )2, em que $\mathrm{Xj}$ = abundância representada pelo número absoluto de cada espécie na área de estudo; Xo = abundância total de espécies na área estudada; e) equitabilidade ou equidade: $\mathrm{J}=\mathrm{H}^{\prime} / \mathrm{Hmax}^{\prime}$, em que Hmax = Log $\mathrm{s}$, em que $\mathrm{s}=$ número de espécies amostradas; e f) índice de Similaridade de Jaccard $(\mathrm{Sj}): \mathrm{Sj}=\mathrm{a} / \mathrm{a}+$ $\mathrm{b}+\mathrm{c}$, em que $\mathrm{a}=$ número de espécies comuns no ambiente $\mathrm{A}$ e $\mathrm{B}, \mathrm{b}=$ número de espécies exclusivas no ponto $\mathrm{A}$ e $\mathrm{c}=$ número de espécies exclusivas no ponto $\mathrm{B}$. A similaridade com relação à composição de espécies entre as praças estudadas foi verificada através da Análise de Agrupamento, utilizando-se o coeficiente de similaridade de Sorensen e média não ponderada (UPGMA). Todos os índices ecológicos e a análise estatística foram obtidos com o auxílio do pacote 
estatístico Statistica (STATISOFT CORPORATION; 2005). Em adição, a frequência das espécies com maior ocorrência foi obtida através da razão número de indivíduos da espécie/número de indivíduos total.

A classificação das espécies em nativa e exótica seguiu a literatura apropriada. A comparação florística com outras regiões brasileiras foi feita através da comparação com outros estudos, tendo como parâmetro o número de espécies.

\section{RESULTADOS}

Foram encontradas, nas sete praças públicas analisadas, um total de 98 espécies de porte arbóreo distribuídas em 43 famílias (Tabela 1). O número total de plantas registradas nas áreas foi de 1.143 indivíduos. As famílias que apresentaram maior riqueza de espécies foram Fabaceae (12 espécies), seguida de Myrtaceae, Cupressaceae (ambas com nove espécies) e Arecaceae (sete espécies). Entretanto, a maioria das famílias (27 famílias $62,8 \%$ do total) teve ocorrência de uma única espécie. Os gêneros com maior riqueza de espécies foram Chamaecyparis, Cytrus, Eucalyptus, Eugenia, Tabebuia e Prunus com três espécies cada um. As espécies com maior ocorrência foram Tipuana tipu (presente nas sete praças), Araucaria angustifolia, Chamaecyparis pisifera, Ligustrum lucidum e Tabebuia alba (em seis praças cada), Eugenia uniflora, Grevillea robusta e Melia azedarach Syagrus romanzoffiana (em cinco praças cada). Dessas, somente Araucaria angustifólia, Eugenia uniflora, Syagrus romanzoffiana e Tabebuia alba são nativas do Brasil, e apenas a última não era nativa da área estudada. As espécies mais abundantes foram, de modo geral, as mesmas que apresentaram melhor distribuição (Tabela 2). As seis espécies mais abundantes eram responsáveis por 39,1\% do total de plantas ocorrentes nas sete praças públicas avaliadas, sendo os demais $60,9 \%$ distribuídos em outras 92 espécies.

Considerando a origem das plantas ocorrentes, 51 espécies eram plantas de ocorrência nativa em território brasileiro. As demais 47 espécies eram plantas introduzidas oriundas de outras partes do mundo. Levando em consideração a vegetação típica da região de estudo, apenas 41 espécies eram nativas da região, enquanto 57 eram espécies consideradas exóticas, oriundas de outras regiões do país e do mundo. Tal diferença entre o número de plantas nativas e exóticas acentua-se ao considerar a abundância de espécies. Dos 1.143 indivíduos registrados, somente $40,2 \%$ do total eram representantes da flora nativa nacional, enquanto $59,8 \%$ do total de indivíduos pertenciam a espécies de origem exótica. Com relação à flora regional, tal diferença fica ainda mais elevada, chegando as espécies exóticas a ocupar $73 \%$ do total, com somente $27 \%$ de plantas nativas.

Os índices ecológicos obtidos nas áreas estudadas foram, de modo geral, similares, embora amplamente variáveis (Figura 2). Apesar de ocorrerem espécies predominantes em cada uma das praças públicas, a riqueza de espécies foi relativamente alta em todas as áreas avaliadas (Figura 2a), com uma média de $30,8 \pm 13,55$ espécies. A maior riqueza foi verificada na praça 3 , onde foram identificadas 47 espécies de plantas arbóreas, enquanto a menor riqueza foi observada na praça 5, com 15 espécies.

A abundância de espécies mostrou-se também relativamente elevada (Figura $2 b$ ). A média foi de 163,3+96,7 indivíduos, sendo a maior abundância observada na praça 6 , com 325 indivíduos, e a menor na praça 5, com apenas 71 exemplares. Considerando a quantidade de indivíduos pelo tamanho das áreas avaliadas, registrou-se uma espécie em cada 109,9 $\mathrm{m}^{2}$ na praça $1,93,6 \mathrm{~m}^{2}$ na praça $2,158,4 \mathrm{~m}^{2}$ na praça 3 , $78,4 \mathrm{~m}^{2}$ na praça $4,90,6 \mathrm{~m}^{2}$ na praça $5,505 \mathrm{~m}^{2}$ na praça 6 e $50,8 \mathrm{~m}^{2}$ na praça 7

Os valores do índice de diversidade, em média $(X=2,66 \pm 0,43)$, foram altos, variando de 1,94 na praça 4 a 3,32 na praça 7 (Figura 2c). Com relação a esses valores, a equidade também apresentou valores altos $(X=0,80 \pm 0,08)$, sendo o menor observado também na praça $4(0,62)$ e o valor mais elevado $(0,90)$, na praça 1 (Figura 2d). De modo inverso, a dominância foi baixa $(X=0,12 \pm 0,08)$, com valores variando de 0,05 na praça 7 a 0,31 na praça 4 (Figura 2e).

Por fim, os valores de similaridade foram relativamente baixos $(0,11$ a 0,37$)$, o que mostra alta diferenciação entre as praças quanto à composição de espécies. A Análise de Agrupamento (Cluster Analysis) confirmou a baixa similaridade entre as áreas estudadas, mostrando a formação de dois grandes grupos (Figura 3). O primeiro, formado pelas praças 3, 7, 4 e 5, tendo as duas primeiras maior similaridade com relação às demais. $\mathrm{O}$ segundo grupo foi formado pelas praças 1, 2 e 6, com as duas últimas possuindo maior similaridade. Apesar da formação desses grupos, a similaridade entre qualquer uma das áreas foi significativamente baixa (Figura 3).

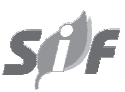

Revista Árvore, Viçosa-MG, v.36, n.4, p.647-658, 2012 


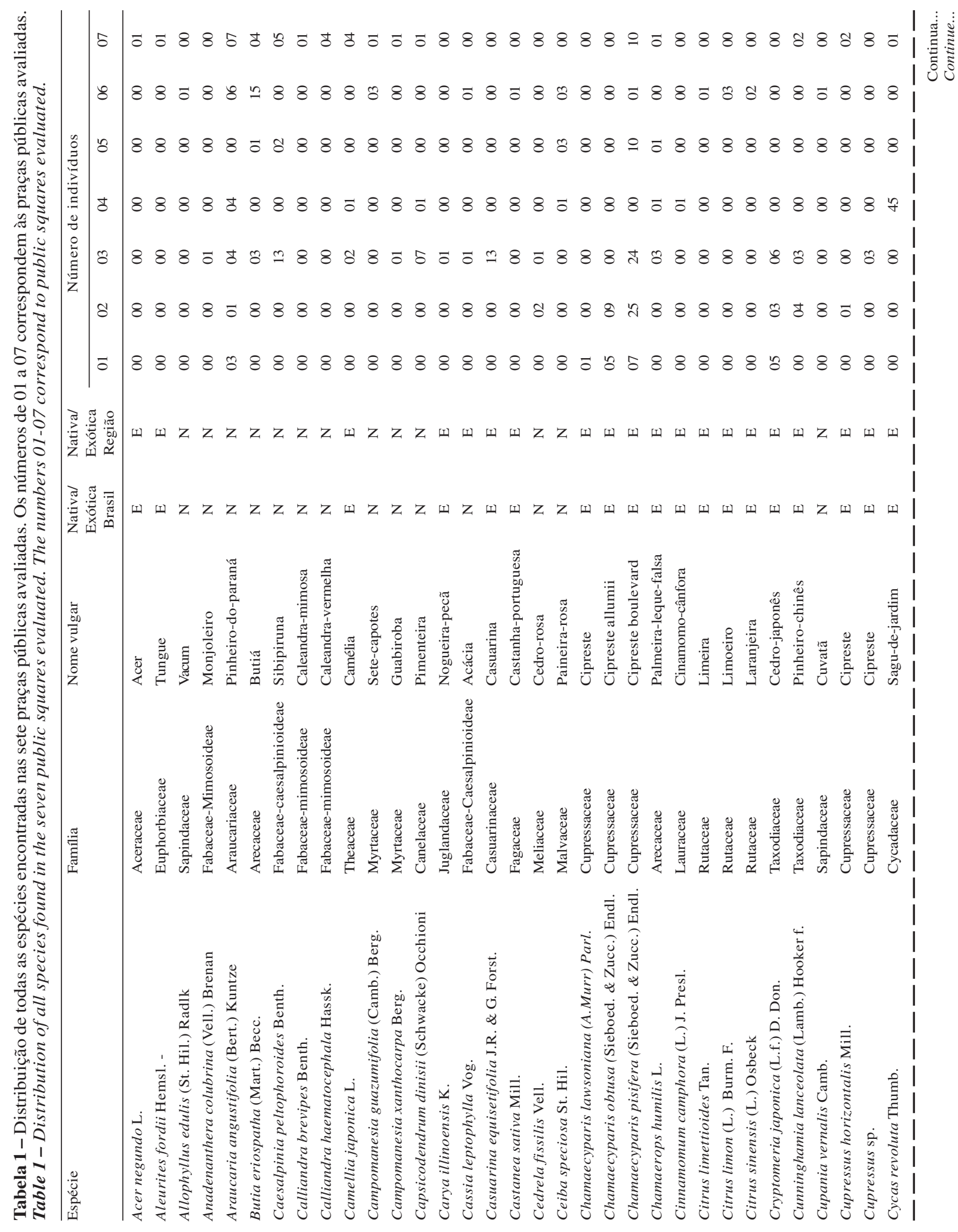

Revista Árvore, Viçosa-MG, v.36, n.4, p.647-658, 2012 


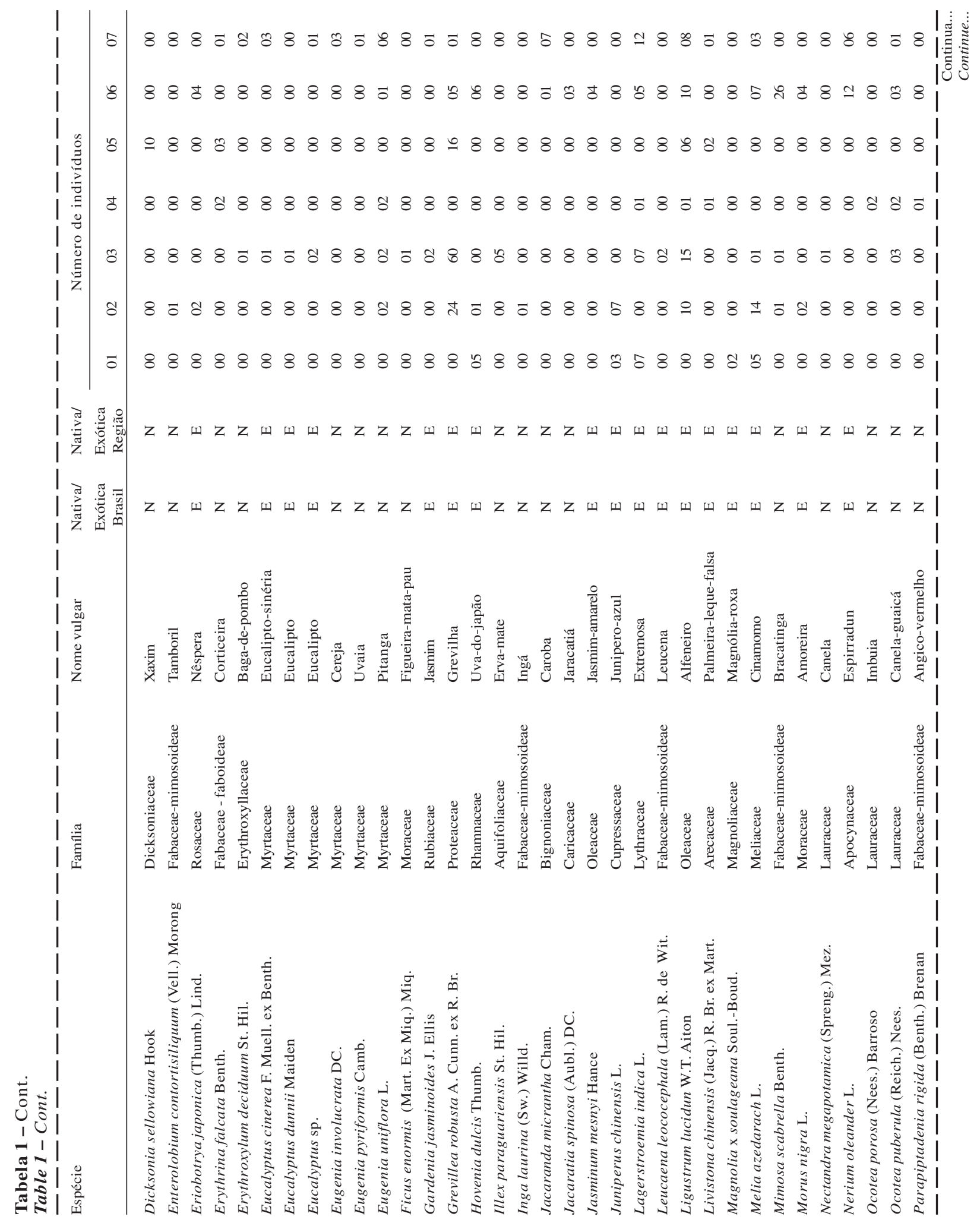




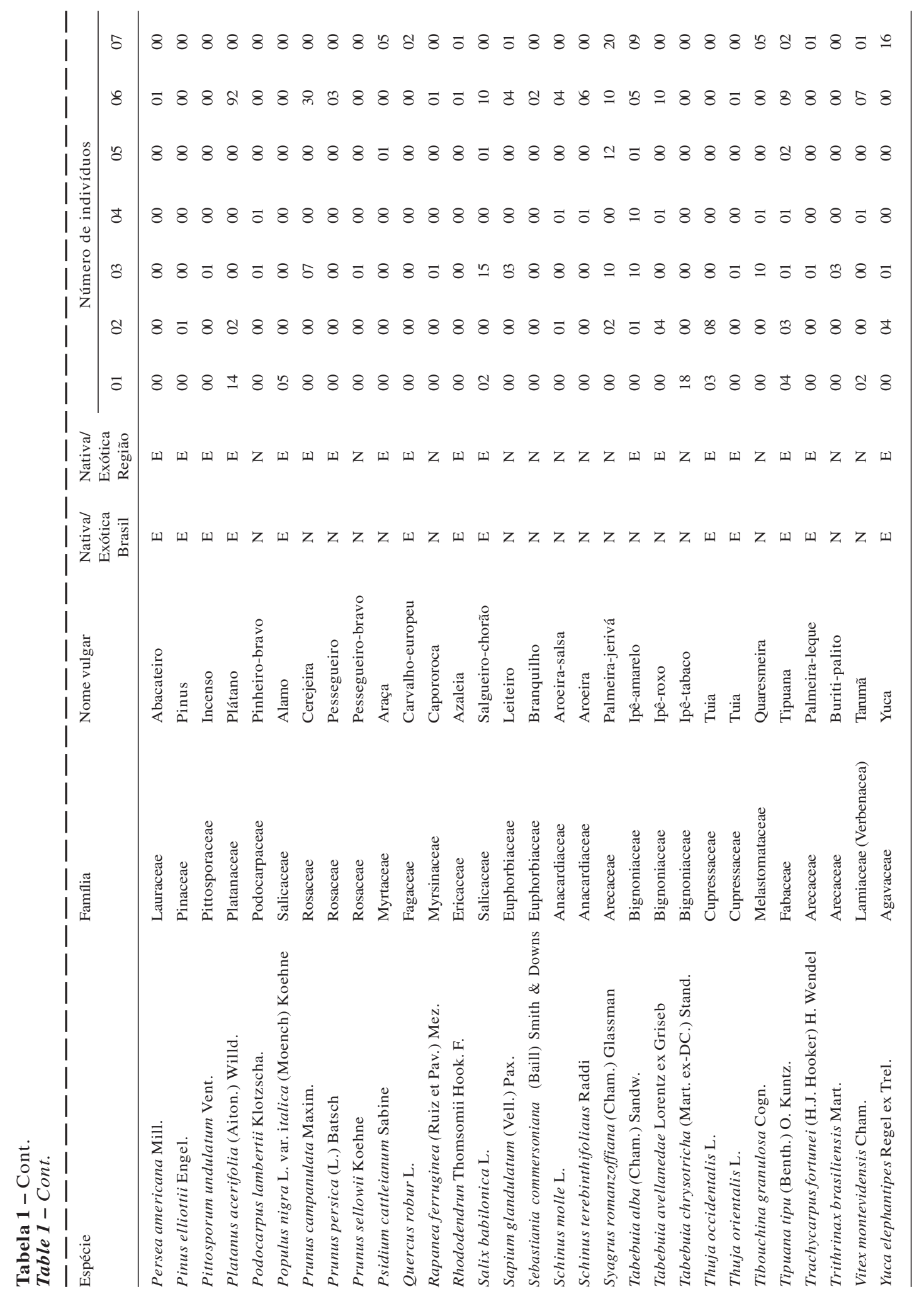

Revista Árvore, Viçosa-MG, v.36, n.4, p.647-658, 2012 
Tabela 2 - Relação das 20 espécies mais frequentes encontradas nas praças públicas do Município de Guarapuava, PR . Table 2 - Relation of twenty species more frequent in the squars publics of municipality of Guarapuava, PR.

\begin{tabular}{llcc}
\hline Nome científico & Nome comum & $\mathrm{N}^{\circ}$ de ind. & $\mathrm{F}(\%)$ \\
\hline Grevillea robusta A. = Cunn. ex R. Br. & Grevílea & 106 & 9,0 \\
Platanus acerifolia (Aiton.) Willd. & Plátano & 106 & 9,0 \\
Chamaecyparis pisifera (Sieboed. \& Zucc.) Endl. & Cipreste & 77 & 6,7 \\
Syagrus romanzoffiana (Cham.) Glassman & Palmeira-jerivá & 54 & 4,7 \\
Ligustrum lucidum W.T. Aiton & Alfeneiro & 50 & 4,4 \\
Cycas revoluta Thumb. & Cica & 46 & 4,0 \\
Prunus campanulata (Maxim.) & cerejeira & 37 & 3,2 \\
Tabebuia alba (Cham.) Sandw. & Ipê-amarelo & 36 & 3,1 \\
Lagerstroemia indica L. & Extremosa & 32 & 2,8 \\
Melia azedarach L. & Cinamomo & 30 & 2,6 \\
Mimosa scabrella Benth. & Bracatinga & 28 & 2,4 \\
Salix babilonica L. & Chorão & 28 & 2,4 \\
Araucaria angustifolia (Bert.) Kuntze. & Pinheiro-do-paraná & 25 & 2,2 \\
Butia eriospatha (Mart.) Becc. & Butiá & 23 & 2,0 \\
Tipuana tipu (Benth.) O. Kuntz. & Tipuana & 22 & 1,9 \\
Yuca elephantipes Regel ex Trel. & Yuca & 21 & 1,8 \\
Caesalpinia peltophoroides Benth. & Sibipiruna & 20 & 1,7 \\
Nerium oleander L. & Oleandro & 18 & 1,6 \\
Tabebuia chrysotricha (Mart. ex-DC.) Stand. & Ipê-de-jardim & 18 & 1,6 \\
Tibouchina granulosa Cogn. & Quaresmeira & 16 & 1,4 \\
\hline
\end{tabular}
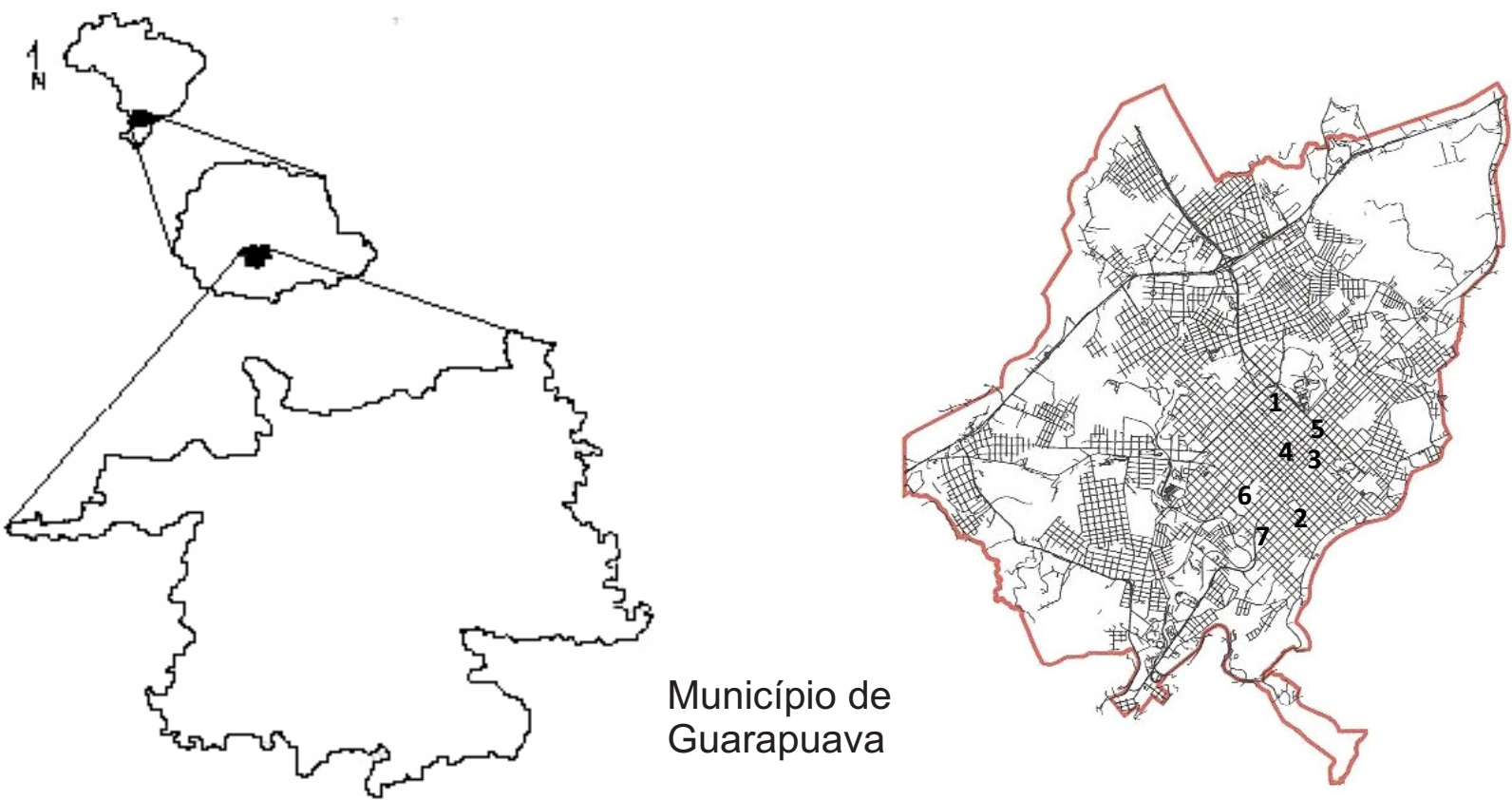

Figura 1 - Localização do Município de Guarapuava (a) e das sete praças públicas (b) dentro do perímetro urbano do município. Figure 1 - Localization of municipality of Guarapuava $(a)$ and the seven public squares $(b)$ within the urban perimeter. 

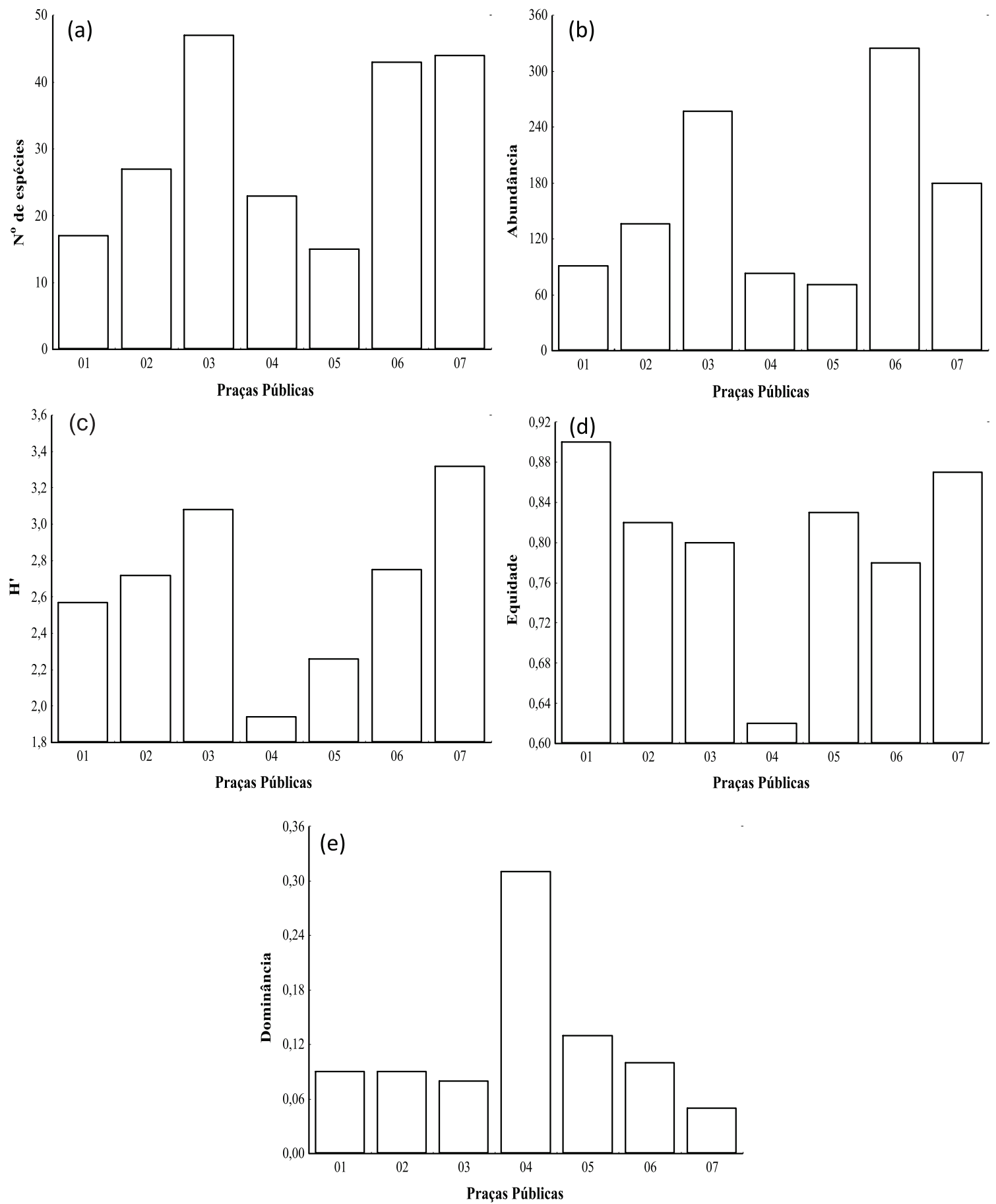

Figura 2 - Valores nominais de riqueza (a), abundância (b), índice de diversidade (c), equidade (d) e dominância (e) de cada uma das sete praças avaliadas.

Figure 2 - Nominal values of richness (a), abundance (b), diversity indice $(c)$ equability $(d)$ and dominance $(e)$ for each squars evaluated.

Revista Árvore, Viçosa-MG, v.36, n.4, p.647-658, 2012 


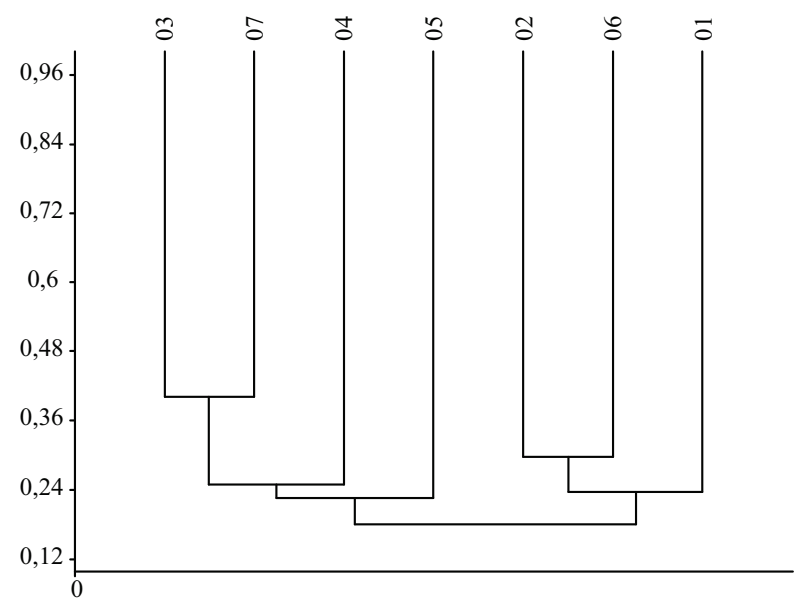

Figura 3 - Dendrograma resultante da análise de Agrupamento das praças públicas avaliadas com base na riqueza e abundância das espécies ocorrentes.

Figure 3-Cluster analisys of public squars evaluated with base in richness and abundance of species occurent.

\section{DISCUSSÃO}

O número total de espécies $(n=98)$ encontrado pode ser considerado alto quando comparado com valores obtidos em outros trabalhos similares. Lima Neto et al. (2007) identificaram as plantas arbóreas de seis praças públicas e 12 avenidas e canteiros centrais da cidade de Aracaju, SE, obtendo um número total de apenas 23 espécies arbóreas. Dantas e Souza (2004) levantaram um total de 132 espécies arbóreas presentes em 24 áreas públicas e privadas do Município de Campina Grande, PB. Com base no número de espécies e de locais avaliados, considera-se que a arborização das áreas estudadas se encontrava bastante diversificada. Já o número de indivíduos, apesar de relativamente alto $(\mathrm{n}=1.143)$, foi, ainda assim, menor que o encontrado nos estudos de Lima Neto et al. (2007) e no de Dantas e Souza (2004), que apresentaram 1.584 e 2.190 indivíduos, respectivamente. Esse menor número de indivíduos pode também ser consequência do menor número de áreas avaliadas neste estudo.

Com relação ao número de famílias observadas $(n=43)$, pode ser considerado alto. Trabalhos similares registraram valores inferiores ao deste estudo. Nesse sentido, Pires et al. (2007) relataram 35 famílias em um diagnóstico realizado na cidade de Goiandira, Goiás, e Lindenmaier e Santos (2008), em levantamento de 21 praças do Município de Cachoeira do Sul, RS, encontraram 45 famílias. A diversidade registrada neste trabalho pode ser resposta à ampla variedade de espécies ocorrentes naturalmente em Floresta Ombrófila Mista, vegetação predominante e, ainda, relativamente bem conservada na região. Outro fator que também contribui com a alta diversidade de famílias é o grande número de espécies ornamentais exóticas presentes, comumente utilizadas em planos de manejo ou arborização de praças públicas.

Entre as famílias que apresentaram maior riqueza de espécies, destaca-se Fabaceae, que corresponde a uma das maiores famílias de angiospermas, com cerca de 18 mil espécies (SOUZA; LORENZI, 2005). Inúmeras espécies dessa família são empregadas amplamente como ornamentais, sendo inclusive a principal família utilizada na arborização urbana das cidades brasileiras (SOUZA; LORENZI, 2005). Myrtaceae também é uma família numerosa e de ocorrência típica em regiões tropicais e subtropicais. É extremamente comum nas formações vegetacionais da região, apresentando grande número de espécies de ocorrência nativa (CORDEIRO; RODRIGUES, 2007). Outro fator importante e que pode contribuir com sua alta representatividade em ambientes como praças públicas é que muitas de suas espécies são frutíferas (p. ex. Campomanesia xanthocarpa, Eugenia uniflora e Psidium cattleyanum), podendo, dessa forma, além de deixar o ambiente mais colorido, proporcionar alimento, principalmente para animais (aves e pequenos mamíferos). As outras duas famílias (Cupressaceae e Arecaceae), também em número bem representadas neste estudo, são tipicamente utilizadas como ornamentais em todo o país. Cupressaceae é uma família exótica, com representantes com formas variáveis, sendo facilmente moldáveis através da poda e, por isso, bastante apreciada em ambientes públicos e privados; e Arecaceae, a qual inclui as palmeiras, que são utilizadas principalmente devido ao seu porte majestoso e à folhagem diferenciada. Praticamente, todas têm potencial ornamental, o que contribui para sua elevada riqueza observada, sendo utilizadas tanto espécies nativas quanto exóticas.

Considerando as espécies mais bem distribuídas, todas são encontradas abundantemente na arborização de grande parte do território brasileiro (LIMA NETO et al., 2007; SILVAet al., 2008; LINDENMAIER; SANTOS, 2008). Destacam-se, entre estas, a tipuana, presente em todas as praças públicas avaliadas e amplamente utilizadas como ornamental, por ser uma planta de porte

Revista Árvore, Viçosa-MG, v.36, n.4, p.647-658, 2012

\section{Siff}


majestoso e com belas flores amarelas. As espécies mais abundantes normalmente são aquelas amplamente utilizadas como ornamentais e advindas de plantio feito pelos órgãos responsáveis pela administração desses locais públicos. Esse é o principal motivo pelo qual se observam tantos exemplares dessas espécies. Alguns táxons, assim como Chamaecyparis pisifera, Grevillea robusta, Ligustrum lucidum e Platanus acerifolia, são tipicamente reportados como ocorrendo em ambientes urbanos, estando sempre entre os mais abundantes (ROSSATO et al., 2008; SILVA et al., 2008; LINDENMAIER; SANTOS, 2008). Loboda et al. (2005) haviam mencionado Ligustrum lucidum como a espécie mais frequente em áreas verdes e espaços públicos do Município de Guarapuava, além de destacar a alta frequência de Tipuana tipu e Grevillea robusta. Coltro e Miranda (2007) também encontraram o Ligustrum lucidum como uma das espécies mais frequentes utilizadas na arborização urbana do Município de Irati, no Estado do Paraná. Essa espécie é amplamente utilizada na arborização urbana, sobretudo nas Regiões Sul e Sudeste do Brasil, onde é possível encontrá-la com extrema facilidade (LOBODAet al., 2005; COLTRO;MIRANDA, 2007).

Apesar da utilização de uma ou poucas espécies, principalmente em ruas e avenidas públicas, é indicada alegando-se o melhor efeito paisagístico (SILVA et al., 2008), a predominância de poucas espécies, além de diminuir a diversidade local, pode trazer alguns problemas, como facilitar a propagação de pragas ou dificultar o trabalho de equipes de poda, pois diversas espécies possuem diferentes épocas para seu manejo mais apropriado (MILANO; DALCIN, 2000; ROCHA et al., 2004).

A origem das espécies ocorrentes nas praças públicas avaliadas é predominantemente exótica, assim como observado em vários outros trabalhos (COSTA; HIGUSHI, 1999; LINDENMAIER; SANTOS, 2008; MACHADO et al., 2006; PIRES et al., 2007; ROSSATO et al., 2008; SILVA et al., 2008). Tal fato se acentua quando se considera a abundância de espécies. De modo geral, tal situação representa falta de preocupação com a conservação e com a flora regional. Silva et al. (2008) registraram apenas 31,5\% de espécies brasileiras nativas em áreas públicas do Município de Franca, no Estado de São Paulo. Dessas, apenas $8,3 \%$ eram representantes da flora regional. Segundo

Revista Árvore, Viçosa-MG, v.36, n.4, p.647-658, 2012 esses autores, tal situação se deve, em parte, à falta de interesse dos órgãos públicos em incentivar e promover o plantio de espécies nativas da região.

Levando em conta as características ecológicas, pode-se considerar que as praças públicas avaliadas possuíam boa condição em número, abundância e diversidade de espécies arbóreas. A alta riqueza média de espécies observada é um ponto positivo com relação à qualidade ambiental, principalmente fitossanitária das áreas avaliadas (LINDENMAIER; SANTOS, 2008). Entretanto, a baixa abundância, demonstrada pela relação entre área e número de indivíduos, e o predomínio numérico de poucas espécies são pontos negativos relacionados com a questão anteriormente descrita. Segundo Grey e Deneke (1978), o limite máximo de frequência de indivíduos por espécie em uma área deve ser entre 10 e 15\%. Das sete praças estudadas, seis apresentavam espécies com frequência superior a $15 \%$ do total de indivíduos (Tabela 1). Apesar disso, são poucas as espécies com elevada abundância, sendo a maioria com poucos representantes. Aliás, essa é uma tendência em ambientes urbanos brasileiros (DANTAS; SOUZA, 2004; MOTTA, 1998; RODRIGUES et al., 1994; SILVA et al., 2008; TEIXEIRA, 1999).

A diversidade média foi relativamente alta $(x=2,66)$, entretanto Lindenmaier e Santos (2008) observaram valor mais elevado $(x=3,86)$ para a vegetação urbana do Município de Cachoeira do Sul, RS. Esses autores consideraram que a diversidade de espécies na área avaliada é de nível intermediário, tendo em vista o alto número de espécies observadas e, ainda, a ausência de espécies com frequência superior a $15 \%$ do total. Nesse sentido, a arborização das praças públicas aqui avaliadas também pode ser considerada como possuindo níveis de diversidade intermediários. Pois, apesar de ocorrerem algumas poucas espécies com elevada frequência de ocorrência, elas interferem pouco nos demais índices ecológicos observados em razão, principalmente, da elevada riqueza de espécies ocorrentes. Tal fato fica mais evidente quando se observam os valores de dominância, expressivamente baixos. Assim, a arborização das praças é relativamente diversa, com distribuição igualitária, comprovada pelos altos valores de equidade.

Por fim, os baixos valores de similaridade observados entre as diferentes praças mostram que a riqueza e diversidade de espécies são altas e bastante variadas 
não só dentro das praças, mas também entre elas. A análise de agrupamento confirmou tal diferenciação e mostrou, ainda, que a proximidade espacial das praças públicas estudadas não tem influência sobre a similaridade de espécies ocorrentes. Isso, por certo, tem relação com a grande diversidade de espécies nativas da região, que são passíveis de serem utilizadas na arborização urbana, devido às suas características morfológicas e ao seu aspecto visual (pequeno e médio portes, exuberantes, com flores vistosas, algumas frutíferas), além da variedade de espécies de origem exótica, cada vez mais utilizadas pelo seu potencial paisagístico e facilidade de cultivo e manejo.

\section{CONCLUSÃO}

A alta diversidade de espécies registradas nas praças públicas avaliadas indica certa qualidade na estrutura física e ambiental desses locais. Entretanto, alguns problemas comuns já reportados em trabalhos neste tipo de ambiente também ocorrem na região, quais sejam: baixo número e abundância de espécies e elevado número de espécies de origem exótica. Apesar disso, tais características ecológicas foram superiores a muitos estudos relacionados. Outro fator positivo é o uso constante de espécies nativas da região, as quais, adaptadas ao ambiente onde ocorrem, auxiliam na qualidade ambiental e fitossanitária das áreas urbanas avaliadas.

\section{AGRADECIMENTOS}

Imensamente a Sebastião Arzírio de Oliveira, pelo auxílio nos trabalhos de campo e pela identificação do material botânico.

\section{REFERÊNCIAS}

COLTRO, E. M.; MIRANDA, G. M. Levantamento da arborização urbana pública de Irati-Pr e sua influência na qualidade de vida de seus habitantes. Revista Eletrônica Lato Sensu, v.2, n.1, p.1-22, 2007.

COSTA, L. A.; HIGUCHI, N. Arborização de ruas de Manaus: avaliação qualitativa e quantitativa. Revista Árvore, v.23, n.2, p.223-232, 1999.

DANTAS, I. C.; SOUZA, C. M. C. Arborização urbana na cidade de Campina Grande - PB: inventário e suas espécies. Revista de Biologia e Ciências da Terra, v.4, n.2, p.1-18, 2004.
GREY, G. W.; DENEKE, F. J. Urban forestry. New York: John Wiley, 1978. 279p.

HARDT, L. P. A.; HARDT, C. Avaliação da qualidade da paisagem como fundamento à gestão urbana e regional: estudo de caso em Piraquara, Paraná, Brasil. In: SIMPÓSIO BRASILEIRO DE SENSORIAMENTO REMOTO, 2007, Florianópolis. Anais... Florianópolis: Sociedade Brasileira de Sensoreamento Remoto, 2007. p.5301-5307.

LINDENMAIER, D. S.; SANTOS, N. O. Arborização urbana das praças de Cachoeira do Sul, RS, Brasil: fitogeografia, diversidade e índice de áreas verdes. Pesquisas, Botânica, v.1, n.59, p.307-320, 2008.

LIMA NETO, E. M. et al. Análise das áreas verdes das praças do bairro centro e principais avenidas da cidade de Aracaju-SE. Revista da Sociedade Brasileira de Arborização Urbana, v.2, n.1, p.17-33, 2007.

LOBODA, C. R. et al. Avaliação de áreas verdes em espaços públicos no município de Guarapuava, PR. Ambiência, v. 1, n.1, p.141-155, 2005.

LOMBARDO, M. A. Ilha de Calor nas Metrópoles - O exemplo de São Paulo. São Paulo: HUCITE, 1985. 244p.

MACHADO, R. R. B. et al. Árvores nativas para a arborização de Teresina, Piauí. Revista da Sociedade Brasileira de Arborização Urbana, v. 1, n.1, p.10-18, 2006.

MILANO, M.; DALCIN, E. Arborização de vias públicas. Rio de Janeiro: LIGHT, 2000. 226 p.

MOTTA, G. L. O. Inventário da arborização de áreas, utilizando um sistema hierárquico para endereço impreciso. 1998. 120f. Dissertação (Mestrado em Ciências Florestais) - Universidade Federal de Viçosa, Viçosa, MG, 1998.

PIRES, N. A. M. T. et al. Diagnóstico da arborização urbana do município de Goiandira, Goias. Revista Brasileira de Biociências, v.5, n.1, p.537-539, 2007.

ROCHA, R. T.; LELES, P. S. F.; OLIVEIRA NETO, S. N. Arborização de vias públicas em Nova Iguaçú, RJ: O caso dos bairros Rancho Novo e Centro. Revista Árvore, v.28, n.4, p.599-607, 2004.

Revista Árvore, Viçosa-MG, v.36, n.4, p.647-658, 2012 
RODRIGUES, M. G. R.; BREDT, A.; UIEDA, W. Arborização de Brasília, Distrito Federal, e possíveis fontes para morcegos fitófagos. In: CONGRESSO BRASILEIRO DEARBORIZAÇÃO URBANA; ENCONTRO NACIONAL SOBRE ARBORIZAÇÃO URBANA, 1994. São Luiz, Anais... São Luiz: Sociedade Brasileira de Arborização Urbana, 1994. p.331-326.

ROSSATO, D. R.; TSUBOY, M. S. F.; FREI, F. Arborização urbana na cidade de Assis, SP: Uma abordagem quantitativa. Revista SBAU, v.3, n.3, p.1-16, 2008.
SILVA, M. D. M.; SILVEIRA, R. P.; TEIXEIRA, M. I. J. G. Avaliação da arborização de vias públicas de uma área da região oeste da cidade de Franca/SP. Revista SBAU, v.3, n.1, p.19-35, 2008.

SOUZA, V. C.; LORENZI, H. Botânica sistemática. São Paulo: Plantarum, 2005. 640p.

TEIXEIRA, I. F. Análise qualitativa da arborização de ruas do conjunto habitacional Tancredo Neves, Santa Maria - RS. Ciência Florestal, v.9, n.2, p.9-21, 1999. 